\title{
ARSR: Committed to Quality and Breaking New Ground
}

\author{
Citation for published version (APA):
}

van Lankveld, J. J. D. M. (2011). ARSR: Committed to Quality and Breaking New Ground. Journal of Sex Research, 48(2-3), 103-105. https://doi.org/10.1080/00224499.2011.560536

DOI:

10.1080/00224499.2011.560536

Document status and date:

Published: 14/07/2011

Document Version:

Publisher's PDF, also known as Version of record

Please check the document version of this publication:

- A submitted manuscript is the version of the article upon submission and before peer-review. There can be important differences between the submitted version and the official published version of record. People interested in the research are advised to contact the author for the final version of the publication, or visit the DOI to the publisher's website.

- The final author version and the galley proof are versions of the publication after peer review.

- The final published version features the final layout of the paper including the volume, issue and page numbers.

Link to publication

\section{General rights}

Copyright and moral rights for the publications made accessible in the public portal are retained by the authors and/or other copyright owners and it is a condition of accessing publications that users recognise and abide by the legal requirements associated with these rights.

- Users may download and print one copy of any publication from the public portal for the purpose of private study or research.

- You may not further distribute the material or use it for any profit-making activity or commercial gain

- You may freely distribute the URL identifying the publication in the public portal.

If the publication is distributed under the terms of Article 25fa of the Dutch Copyright Act, indicated by the "Taverne" license above, please follow below link for the End User Agreement:

https://www.ou.nl/taverne-agreement

Take down policy

If you believe that this document breaches copyright please contact us at:

pure-support@ou.nl

providing details and we will investigate your claim.

Downloaded from https://research.ou.nl/ on date: 26 Apr. 2023 


\section{EDITOR'S INTRODUCTION}

\section{ARSR: Committed to Quality and Breaking New Ground}

As the incoming editor of the Annual Review of Sex Research (ARSR), I was asked to state my goals for the forthcoming series of issues, and I gladly take this opportunity. From the early years of my own work in sex research, the $A R S R$ has been one of my most important resources. Its contributions always brought me comprehensiveness and scholarly excellence, whatever the topic of the article. Thus, it may not come as a surprise that I am dedicated to maintain this high standard of quality and comprehensiveness of the reviews that make it into ARSR. Below, I highlight some of the quality criteria that color my view of what are good and worthwhile review articles.

What determines the quality of review articles? First of all, it needs to be emphasized that the quality of any narrative or meta-analytic review necessarily depends on the quality of the studies aggregated by the authors ("compiled excellence" vs. "garbage in, garbage out"). One of the noteworthy findings in this respect is that bad research typically tends to overestimate the magnitude of its demonstrated effects. Conversely, studies of higher methodological quality tend to be associated with smaller effect sizes. Methodological rigor, thus, may help to keep the researcher from erroneously finding what he or she desires most to find in the absence of a true effect. Unfortunately, this association of research quality and outcome magnitude can - until now - only be gleaned from publications in other fields of study. For example, Klein, Jacobs, and Reinecke (2007) found that, compared with earlier studies, more recent studies of cognitive-behavioral therapy for adolescent depression tended to yield smaller effect sizes (but with narrower confidence intervals), but also that higher-quality studies produced smaller effect sizes. This was recently replicated in a meta-analysis of studies of psychotherapy for adult depressive disorder (Cuijpers, van Straten, Bohlmeijer, Hollon, \& Andersson, 2010). Such direct association of methodological quality with the outcome of investigations should caution ARSR authors, and reviewers who evaluate $A R S R$ manuscripts, not to lean on publications with unclear or dubious methodology. I am happy to have already discovered that authors indeed are critical about the choice of articles for their manuscripts, and that $A R S R$ reviewers do pay critical attention to the quality of the publications that are reviewed and referenced.

Causality is another crucial issue in the research on which review articles are based. Most of the study designs that are used in sex research are correlational. True experimental work that allows for strong inferences regarding causality and directionality is, in many cases, not possible or extremely difficult to realize. This imposes major constraints on our scientific discourse about causes and effects when writing about sex research. Authors and reviewers should be - and apparently are - critical of the line of reasoning applied when reviewing such correlational data.

ARSR is published under auspices of the Society for the Scientific Study of Sexuality (SSSS). Literature reviews typically look back to summarize what empirical study has brought us thus far. A recent SSSS description of the ARSR mission reflects this practice:

\begin{abstract}
ARSR reviews should represent comprehensive coverage of the literature, citing both historical and contemporary literature as appropriate. Citations should be broad in scope, not simply focus on the author's own work. The review should provide a good summary of the field and identify the major issues, existing controversies, and disparities in findings and methodologies. As part of this last point, attention should be given to the strength of the methodologies and findings of various studies as well as the conclusions based thereon.
\end{abstract}

Besides looking back and creating a comprehensive and scholarly tableau vivant of the topic at hand, I consider it equally important that $A R S R$ articles look ahead and so inspire other researchers. For this purpose, it is necessary that review authors, because of their superior knowledge of the empirical database and the "major issues, existing controversies, and disparities in findings and methodologies," transcend existent knowledge and attempt to enhance our theoretical understanding by formulating new or improved model accounts of the topic under scrutiny. This will stimulate other researchers to design critical tests of such models and, thus, help to advance our field of study. 
One of the questions that arise in this context concerns timing. How large must the database in a new field be before it is productive for authors to write a review of an area? Should reviews be held back until a subject has received sufficient scientific attention, reflected in large numbers of published studies to, among other purposes, enable the hetero- or homogeneity of findings to be judged; or, should reviews be allowed to focus on newly opened avenues of research, give a preliminary overview, and outline knowledge gaps and interesting future directions of study? There is probably no single, correct answer to this question. I favor the simple solution and encourage authors to do both: write excellent reviews on well-studied issues and write stimulating reviews of emergent fields.

This is how I interpret $A R S R$ 's mission: to review relevant sex research for the purpose of providing great overviews and also to give a new impetus to sex research by uncovering promising developments. I hope to invite many of you to realize one or both of these ambitions. I also hope to receive your assenting responses upon being invited both to write and to review.

In this 2011 issue of $A R S R$, you will find eight review articles.

Hinchliff and Gott have extensively researched the accessibility of sexual health care for elderly women and men in the United Kingdom. They identified major roadblocks to seeking medical help for sexual concerns that related both to the patient and the doctor. Patients are less hesitant to ask for help if their doctors had raised sexual issues during an earlier routine visit. However, as their review demonstrates, doctors often do not actively pursue sexual health management of elderly patients, and were often found to have limited knowledge of later-life sexuality issues. These findings have significant implications for sexual well-being in later life if, to quote the authors, "the doctor does not ask and the patient does not tell."

De Graaf and Rademakers address the problems researchers may face when they attempt to investigate the sexual behaviors and experiences that prepubertal children display, and that can be interpreted as sexual or as precursors of adult sexuality. The authors summarize the research methods that are used to study childhood sexual behavior and feelings, as well as their advantages and limitations. Childhood sexual behaviors and feelings are mostly studied using observational or retrospective methods. In these approaches, only adult perspectives are taken, and the child's perspective is lacking.

Mustanski, Newcomb, Du Bois, Garcia, and Grov present an extensive review of the empirical literature on HIV in young men who have sex with men, who currently represent the majority of young people infected with HIV annually in the United States. They review the epidemiology, risk factors and protective factors, and the outcomes of interventions in this field.
The authors outline an ambitious research agenda for this field including, among others, a focus on the promotion of resilience factors and on the role of family influences. Regarding intervention research, they emphasize interventions that go beyond the individual level that is usually addressed and that target partnership-, community-, and social network-related factors.

Hayes reviews linear and circular models of the female sexual response. The number of direct empirical comparisons between models is still limited but nonetheless suggests that most women identify with linear models of the female sexual response. However, the view that circular pathways accurately reflect some aspects of female sexual response increasingly receives support.

Gender differences within a broad range of behaviors and dimensions of psychological functioning have been the topic of many comparative investigations. Although earlier reviews suggested that sexuality is one of the few domains in which gender differences might be substantial, more recent work indicates that this discrepancy between men and women is smaller than expected. In this issue, Petersen and Hyde review research on gender differences in sexual attitudes and behaviors, particularly with respect to differences in heterosexual intercourse, masturbation, pornography use, attitudes toward premarital sex, and same-gender sexuality. The evidence covered in their review was restricted to meta-analyses and large national datasets, which both have unique methodological advantages.

Meuleman reviews the recent literature on the impact of the metabolic syndrome on male sexual health, as well as developments in the management of sexually dysfunctional men who are diagnosed with the metabolic syndrome. The metabolic syndrome, a cluster of risk factors for cardiovascular disease, appears to be increasing worldwide. This syndrome has a negative impact on male sexual function through, on the one hand, its relationship with cardiovascular disease risk and, on the other hand, its association with hypogonadism and associated psychosocial factors. The metabolic syndrome is considered to pose an important threat to male sexual health. Besides established pharmacological and hormonal interventions, lifestyle modification programs are currently being investigated, and may turn out to be important tools in the management of patients with the metabolic syndrome.

Smith and Pukall review the literature on relationship adjustment and sexual satisfaction among women with provoked vestibulodynia, the most prevalent type of sexual pain disorder. Controlled investigations demonstrate the association of provoked vestibulodynia with lower sexual satisfaction, but not with general relationship discord and maladjustment.

Finally, Snowden, Craig, and Gray review the evidence gathered using indirect measures of cognition 
among sex offenders - specifically, of child sex offenders (those that have victims that are legally under the age of consent) and adult sex offenders (rapists). Indirect measures of cognition provide a relevant window that allows for the exploration and testing of models of cognitive processes that are associated with paraphilic sexual preference, which has an important link to sexoffending behavior. The authors review studies that have used a range of indirect techniques (e.g., the Implicit Association Task and the Lexical Decision Priming Task) and discuss the strengths and weaknesses of this research.

\section{References}

Cuijpers, P., van Straten, A., Bohlmeijer, E., Hollon, S. D., \& Andersson, G. (2010). The effects of psychotherapy for adult depression are overestimated: A meta-analysis of study quality and effect size. Psychological Medicine, 40, 211-223.

Klein, J. S., Jacobs, R. H., \& Reinecke, M. A. (2007). Cognitivebehavioral therapy for adolescent depression: A meta-analytic investigation of changes in effect-size estimates. Journal of the American Academy of Child and Adolescent Psychiatry, 46, 1403-1413.

Jacques van Lankveld Editor, Annual Review of Sex Research 